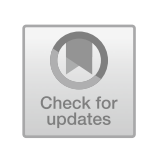

\title{
I Make the World
}

The essential creativity of human beings runs as a theme throughout our history and culture. We see ourselves as "man the maker" and, in modern scientific terms, date the origin of homo sapiens back to the day that man made the first tool. We feel that our creativity somehow separates us from the lower animals and defines our humanity.

In Western religious terms, our creativity has sometimes been seen as the reason for our humanity, the raison d'etre of human existence. This theme appears, for instance, in the Jewish mystical tradition, which argues that God made man because he needed a partner in creation, ${ }^{1}$ and in the philosophy of Henri Bergson, who believed that the whole purpose of the evolutionary process was God's "undertaking to create creators." In Chinese philosophy, the triad Heaven-Man-Earth, sees Man as the bridge who can bring the Way of the Tao to earth and then create a civilization here that will reflect the way of Heaven.

We certainly feel this about ourselves in small ways as we go about our daily lives, and if we reflect on our behavior, we can see that a "creative urge" motivates much of it. Simple things like children's first paintings or fascination with Lego bricks; the later wish to build models, carve soap, make clay pots and baskets; the adult love for do-it-yourself and the wish to decorate both ourselves and our homes are all basic expressions of the same drive that motivates others to write poems or symphonies or to

${ }^{1}$ Gershon G. Scholem, Zohar: The Book of Splendor.

(C) The Author(s) 2022

D. Zohar, Zero Distance, https://doi.org/10.1007/978-981-16-7849-3_10 
articulate new spiritual views. And of course scientific discovery and the technological innovation so vital to today's society and business depends on the constant creativity of scientists and employees.

In past, apart from religious accounts, any explanation for human creativity, or indeed any full account of exactly what creativity $i s$, remained somewhat mysterious. Any sensitive person could notice the difference between an article made by a human craftsperson and those made by a mechanical assembly line turning out thousands of identical objects, but it was not easy to explain why craftspeople are creative and machines are not. The same question lies at the heart of our current wish to design AI systems that can mimic, or even exceed, human ingenuity. Ironically, the explanations now being offered by quantum physics, neuroscience, and complexity theory indicate that creativity is not unique to human beings.

Discoveries being made in thermodynamics as early as the 1980s demonstrated that living systems can get around the limitations of the Second Law of Thermodynamics, which claim that, due to entropy, everything in the universe is running down, or falling into disorder. Ilya Prigogine's Nobel Prize-winning work on "dissipative," or "open systems," demonstrated that some systems, including all living systems, can create order which is both stable and dynamic, ${ }^{2}$ and Prigogine's discovery led directly to the rise of complexity science and its description of the complex adaptive systems (CAD's) that I have already referred to so often in this book. CAD's are creative, stable, adaptive, and evolutionary, describe how all living systems succeed, and we have seen that their science is now being applied to human social systems. It is because we humans are, by our nature, CAD's, and CAD's are, by their nature, creative, that we have a natural mental and biological impulse, or urge, to be creative. CAD's are, of course, the inspiration for the design of Haier's RenDanHeyi management model, and provide the scientific basis for Quantum Management Theory.

Discoveries in neuroscience during these past fifteen years tell us even more about the nature of our creativity. It has become almost common knowledge by now that the human brain is not hard-wired. We don't just grow new neurons and new neural connections until we have reached an age of maturity that equips us to deal with the everyday challenges of life in our culture. Our brains don't stop growing at some age limit like

2 Ilya Prigogine and Isabel Stengers, Order Out of Chaos. 
eighteen or twenty. Instead, they are "plastic," possessing the capacity always to grow new neurons and ever more complex neural connections throughout our entire life span. And we do so whenever we are faced with a new challenge or are responding to some new experience for which we were not previously equipped, responding to something that stimulates us and makes us "think." Our brains themselves have infinite potential. And because of the mutually creative observer/observed relationship in quantum physics, this gives us both the infinite potential to create an ever richer world, and an infinite potential to create and recreate ourselves.

\section{MAKE Myself}

The RenDanHeyi management model rests on the assumption that, as employees recreate their products, they will recreate themselves-add to their knowledge, acquire more skills, realize more of their potential to serve the company. On a still wider scale, this is also the assumption of the quantum world view. In the participative universe described by quantum physics, as observers make reality with their observations of it, they are at the same time making themselves. As we have seen, the observer/observed relationship is a cocreative relationship. In the same way, as quantum persons make the world with our questions, decisions, and actions, each of us also recreates ourselves. We are not victims of reality; we are its makers. We are not victims of our fate; we make our fate. This self-creation happens inevitably to some extent during the years of childhood and growing up, or if we have to face some challenge in the course of life that requires a new learning experience. But we can also do more to grow ourselves and enrich our lives. By doing the kind of things mentioned in the previous chapter-extending and varying our experiences, adding to our learning, going outside our comfort zone to listen to and reflect on views different than our own, celebrating diversity in every way possible, finding meaning in our work. And the resulting, constant, self-creation is not just "a way of life," it is in fact possibly the essential purpose of our lives, the duty of our lives.

Just as Chinese philosophy has always stressed the moral duty of selfcultivation, quantum philosophy sees self-recreation as a moral principle of the good life. The universe constantly evolves toward ever greater complexity, and thus the creation of ever more order and information. As creatures that are fully part of the universe and its Way, it is natural that we do the same. In the quantum world view, which sees every person 
as possessing infinite potential, it is surely the built-in purpose of our human lives to develop as much of that potential as possible. And as both RenDanHeyi and Quantum Management argue, it should be a builtin purpose of the companies we work for to enable us to do so. By enriching ourselves through constant self-creation, we will be enriching our companies, our world, and even the fabric of reality itself.

\section{We Are Responsible for the World}

Since it is we who create ourselves and the world in which we live, it is we who are responsible for these selves and this world. In the end, we make the world through the choices that lead to our decisions and our actions. But this leads to the obvious questions: how are we to know right from wrong? On what authority are we to base our moral and other choices? These questions are particularly urgent at a time when there appear to be no clear or agreed-upon moral or behavioral goal posts to guide us, when a spirit of "anything goes" or "whatever is good for me" seems to reign supreme in both personal and business life. As my daughter said to me when she was fifteen, "It is very difficult to be my age today. You and Dad are always changing your minds about what it is ok for me to do or not do, and none of the other adults in my life seem to know what they are doing either. I just have to make the whole thing up for myself as I go along."

Until two generations ago, people in the Western world, at least, would have looked to their religious beliefs for moral guidance and what was required of them to be a good person. Afterall, God's will was clearly spelt out in the Bible or the Koran, and all we had to do to make the right choices was obey. But today, the vast majority of people in the Western world who adhere to any religious tradition, if they do so at all, do so for social or identity reasons. Young people like my now fourteen-yearold grandson find religion totally irrelevant, "useless and boring," as he describes it. If they believe in anything, it is science, and science has not been very good at articulating a moral perspective. And yet in the East, particularly in China, an understanding of how the universe works, the Way (tao) of the universe, was the very basis of human morality.

As we saw in Chapter 5, Taoism taught that each of us has the whole universe within us. Confucian philosophy, which held that human nature is essentially good and that there is a natural moral or ethical resonance between Heaven and the human, believed that we are born with 
liangzhi-a "moral intuition" or "understanding" of the Way (tao) of the universe, and that we can strengthen this through moral self-cultivation. Thus the reason that self-cultivation was a fundamental principle of Chinese philosophy, and is still a strong value in modern China today. Self-creation is seen as the way we become fully human, and capable of mirroring the harmonious coherence of Heaven here on Earth. As the great contemporary Chinese philosopher Tu Wei-Ming expresses it,

The precondition for us to participate in the internal resonance of the vital forces in nature is our own inner transformation. Unless we can first harmonize our own feelings and thoughts, we are not prepared for nature, let alone for an "interflow with the spirit of Heaven and Earth." It is true that we are one with nature. But as humans, we must make ourselves worthy of such a relationship. ${ }^{3}$

If readers have understood the argument of this book so far, they will know that Quantum Management's insistence that companies (and other forms of social organization) must become complex adaptive systems if they are to succeed is based on the quantum understanding that we are fully part of nature and the universe, and that what works best for them will work best for us. Thus, just as the I Ching advises the leader that "the way to success lies in apprehending and giving actuality to the Way of the universe (tao)," Quantum Management advises leaders that the way to success is to follow the principles of quantum physics and implement them in their organizations. And the same applies to the moral and other decisions we make in our personal lives.

Our Western word for liangzhi is, of course, "conscience." We view conscience as our moral compass and see it as an unfailing inner perception of right and wrong. In my own past work, I have associated conscience with our SQ, or "spiritual intelligence," and have argued that we have this ability to know and understand the way and meaning of the quantum universe because our own bodies and our minds follow the same physical principles by which the universe itself works. Our own, mental and biological, quantum fields resonate with other quantum fields in nature and the universe. It is important to understand that the principles driving the self-organizion of the quantum universe are not rules or "commandments" like those spelt out in the Bible, but

3 Tu Wei-Ming, Confucian Thought, p. 9. 
instead principles and values that can guide the decisions and actions made by our free will. This quantum nature of ours can be thought of as "the central operational system" that guides our moral choices and decisions, just as a quantum company's central operational system guides the self-organization of employee activity.

This argument, very similar to that made by traditional Chinese philosophers for the origin of liangzhi, was the basis of my deriving the Twelve Principles of SQ from the twelve defining qualities of complex adaptive systems (living quantum systems). Those same Twelve Principles appear in Chapter 13 of this book, adapted as the Twelve Principles of Quantum Leadership. The first of the Twelve Principles of SQ, or Quantum Leadership, is "Self Awareness"-knowing who I am, what I truly believe in, what I value, what my real purpose is. Reflecting on these things gives me access to knowing that I am part of nature and the universe and what are the "good" human values and purposes that reflect this. As the great Confucian philosopher Mencius wrote, "For a man to give full realization to his heart is for him to understand his own nature, and a man who knows his own nature will know Heaven." 4 Further access to distinguishing "good" or "moral" decisions and actions from "bad" ones results from knowing the "good" and "bad" forces that lead to either creation or destruction in the universe and nature.

According to quantum cosmology, there are two opposing forces in the universe-coherence, the creative force that brings things together through the power of relationship and creates order, and entropy, the destructive force that tears things apart and creates chaos. These could be the cosmic origins of what we call Good and Evil. Life brings order out of chaos through living systems (complex adaptive systems) that are internally coherent and harmonious, thus stable, adaptive, and evolutionary. All living systems, like the quantum systems that make up the material world out of which they arise, are essentially creative because they are always larger than the sum of their parts. They add something to what existed before. They are also self-organizing. In conscious human beings, this principle of self-organization is expressed through our free will. We make the decisions, we take the actions that make the world in which we live. It is we who can make it a better world and ourselves better people. And the laws of physics can guide us.

${ }^{4}$ Quoted in Tu Wei-Ming, ibid., p. 61. 
Quantum physics tells us that the world is created by the formation of relationships and destroyed by the destruction of relationships, so our moral work takes place through the kind of relationships we are within ourselves and the relationships we make with others. Actions or decisions that create disharmony within ourselves, or between ourselves and others, that put us "at war" with ourselves or others, that destroy relationships, are aligned with the destructive force of entropy, and are thus "bad" actions or decisions. Actions or decisions that create inner harmony or harmony with others, that build relationships, are aligned with the creative force of the universe, and are thus "good" actions or decisions. This is true both in our personal lives and in the actions and decisions we may take as employees or leaders. If we build good and harmonious relationships with others, other individuals, other companies, other nations, we are adding to the desired greater coherence of both the social world and the material universe. If we build bad ones, we fragment them.

This insight, plus the quantum insight that, as everything is connected to everything, everything is part of everything, that there really are no others, leads to the simple, guiding principle of quantum morality that itself mirrors the Golden Rule: When in any relationship, do onto others as you would have them do onto you-because those "others" are you. And for leaders of companies or nations, quantum morality would fully reflect the "moral imperative" of the philosopher Immanuel Kant: Always behave in a way that it would be alright if all others behaved that same way.

Building good human relationships is, of course, not the only way that our adult creativity can contribute to greater order and coherence in our world and in the universe. Each kind of "making" that we do brings something new into the world-making a good meal, making a beautiful article or creating a beautiful space, making an innovative tool or product, making a great company, making knowledge through discovery, are but a few. And, because we have the gift of language, we can make (and destroy) things by relating words. Words brought together to convey truth are creative, and therefore "good" relationships; lies and misinformation are destructive, and therefore "bad" relationships, words of love or compassion "good"; those conveying hatred or cruelty, or simply cold disregard, are "bad," etc.

Thus moral choices, and decisions between "good" and "bad," grounded in what quantum physics now tells us about the universe, are in no way radically different from those grounded in "the wisdom of 
the ages"-the world's great philosophical and spiritual traditions and the wise advice of those inspired by them. But the quantum world view does offer a new language for speaking these old truths, and a new source of authority-ones that might appeal to those so currently unmoored by the amorality, materialism, selfish individualism, and lack of any higher meaning licensed or occasioned by the bleak and corrosive Newtonian world view, and unable to find guidance in the seeming irrelevance of the old language and its sources of authority.

As a summary to these past five chapters that have presented how quantum physics invites us to understand the nature of a person, I will quote these words from Tu Wei-Ming. Tu draws his authority from the Confucian tradition, but the very same conclusions are drawn from the authority of quantum philosophy:

A human being is an active participant of an agelong biological line, a living witness of an historical continuum, and a recipient of the finest essences in the cosmos. Inherent in the structure of the human is an infinite potential for growth and an inexhaustible supply of resources for development. A person's selfhood embodies the highest transcendence within its own reality; no external help is needed for the self to be fully realized....The self is the center of a network of relationships in the human community and must recognize that it is an integral part of a holistic reality...[To quote Mencius,] "All the ten thousand things are there in me. There is no greater joy than to find, on self-examination, that I am true to myself." 5

5 Tu Wei-Ming, ibid., pp. 60-61. 
Open Access This chapter is licensed under the terms of the Creative Commons Attribution-NonCommercial-NoDerivatives 4.0 International License (http:// creativecommons.org/licenses/by-nc-nd/4.0/), which permits any noncommercial use, sharing, distribution and reproduction in any medium or format, as long as you give appropriate credit to the original author(s) and the source, provide a link to the Creative Commons license and indicate if you modified the licensed material. You do not have permission under this license to share adapted material derived from this chapter or parts of it.

The images or other third party material in this chapter are included in the chapter's Creative Commons license, unless indicated otherwise in a credit line to the material. If material is not included in the chapter's Creative Commons license and your intended use is not permitted by statutory regulation or exceeds the permitted use, you will need to obtain permission directly from the copyright holder.

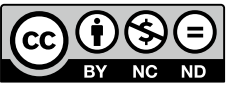

